\title{
Prevalence of Calcaneal Fractures in Our Hospital in Central Europe
}

\author{
Gharaibeh $\mathrm{A}^{1 *}$, Gharaibeh $\mathbf{M}^{2}$, Al wadiya $\mathrm{A}^{3}$, Stolfa $\mathrm{S}^{4}$ and Lacko $\mathbf{M}^{5}$ \\ ${ }^{1}$ Department of Orthopaedics and musculoskeletal trauma, Louis Pasteur University \\ Hospital, Slovakia \\ ${ }^{2}$ Consultant of Oral \& Maxillofacial Surgery, Princes Basma Teaching Hospital, Jordan \\ ${ }^{3}$ Department of Orthopaedics, Royal Derby Hospital, UK, Orthopaedic Surgeon, UK
}

Mini Review

Volume 3 Issue 1

Received Date: January 01, 2018

Published Date: January 31, 2019

DOI: $10.23880 /$ jobd-16000170

${ }^{4}$ Department of Orthopaedics and musculoskeletal trauma, Louis Pasteur University Hospital, Slovakia

${ }^{5}$ Orthopaedic Surgeon, Louis Pasteur University Hospital Kosice, Slovakia

*Corresponding author: MUDr. Ahmad Gharaibeh, MPH, PhD, Orthopaedic Surgeon, Assistant professor, Teaching Department of Orthopaedics and musculoskeletal trauma, UPJS, UNLP, Kosice, Slovakia, Tel: +421948612693; Email: gharaibeh@seznam.cz

\section{Abstract}

Objective: To analyse the epidemiology of patients suffering calcaneal fractures.

Methods: This is a retrospective study of patients with calcaneal fractures hospitalized in the teaching department of Orthopaedics and Traumatology and in central between 2014 and 2018.

Results: The work presented retrospective study to evaluate the Incidence of calcaneal fractures in NSP UNLP hospital. We retrospectively studied 15787 patients with bony fractures in our hospital and trauma clinic in emergency department from 1.1.2014 to 31.12.2018, from our records, 156 patients had calcaneal fracture (1\%).

Conclusion: The research revealed a rare incidence of calcaneus fracture, affecting men 4 times more than women due to nature of work and daily activities. Calcaneal fracture is common cause of disability. The results of this study are expected to contribute to providing an information base that helps planners and decision makers in developing appropriate strategies to deal with safety at work site.

Keywords: Calcaneum; Epidemiology; Fracture; Prevalence; Incidence

\section{Introduction}

A Calcaneal fracture usually occurs after a fall from height or road traffic accidents. Pathoanatomically we classified an extra articular, intra articular and anterior process fractures [1-3]. The most used classification in practice is Sanders classification which is based on the number of articular fragments seen on the coronal view of computer tomography (CT) scan image at the widest point of the posterior facet (Table 1) [2,4,5].

Type I Non-displaced

Type II One fracture line in the posterior facet

Type III Two fracture lines 


\section{Journal of Orthopedics \& Bone Disorders}

Type IV Comminuted

Table 1: Sanders classification. Although conservative treatment can achieve a good results in patients with type I calcaneal fractures when used in patients with other types of fractures, the incidence of early subtalar arthritis is higher in patients managed no-surgically than in those managed surgically [3-5].

After operation there are many complications like wound complications, Subtalar arthritis, lateral impingement with peroneal irritation, damaged flexor hallucis longus, compartment syndrome and malunion. Calcaneal fracture causes significant long-term disability, which is serious economic problem for patients and their families [6,7]. Incidence of calcaneal fracture in Scotland was 11.5 per 100,000 populations per year [7].

From our experience, a significant number of these injuries occur following low energy trauma in osteoporotic bone, in which the predominant population is elderly and female. In addition, a large number of fractures occur in young patients [7].

\section{Material and Methods}

This is a retrospective study of patients with calcaneal fractures hospitalized in the teaching department of Orthopaedics and musculoskeletal Trauma between 1.1.2014 and 31.12.2018. All patients were examined by computer tomography (CT scan) evaluated by radiologists and we evaluated the clinical status and radiological findings of the patients.

- Purpose of the work: The main objective of our work is to determinate the incidence of calcaneal fractures in our region.

- Location: University Hospital - UNLP SNP with 1356 beds, is the second largest Slovak hospital and provides highly qualified health care to patients not only from the Kosice area but in specific cases for the whole Eastern Slovakia.

- Study Population: All patients with fractured heel bone in our hospital.

- Study period: From 1 January 2014 to 31 December 2018.

- Data collection: The data will be collected from the UNLP trauma clinic SNP.

- Data Analysis: Analysis of data and results was processed using statistical features of Microsoft Excel.

\section{Results}

The work presented retrospective study to evaluate the Incidence of calcaneal fractures in NSP UNLP hospital. We retrospectively studied 15787 patients with bony fractures in our hospital and trauma clinic in emergency department from 1.1.2014 to 31.12.2018 from our records, 156 patients had calcaneal fracture (1\%). 36 patients were female $(22 \%)(\mathrm{p}<0.01)$ and 120 were male patients (88\%) (Figure 1).

\section{Calcaneus fractures by gender}

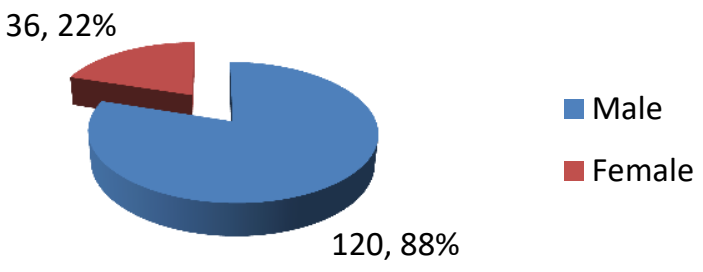

Figure 1: Calcaneus fractures by gender.

All patients were clinically examined and computer tomography (CT scan) was performed. In Slovakia the age of paediatric orthopaedic patient is between 0-19 years old. 17 patients with calcaneal fracture are children (0-19 years) and 139 adults (above 19 years old) (Figure 2). In our study we excluded fractures of head, sternum and ribs.

\section{Calcaneus fracture by age}

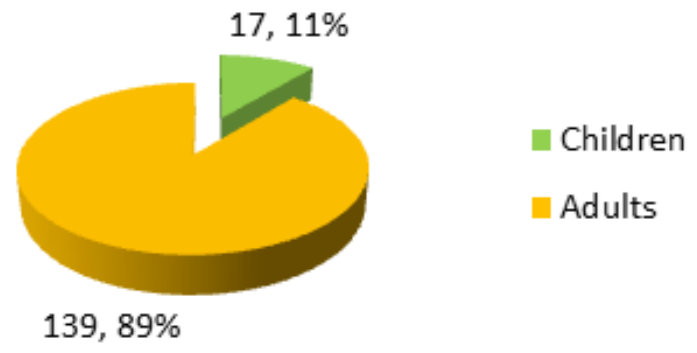

Figure 2: Calcaneus fractures by age.

Tarsal bone fractures are 396 in five years but calcaneal fractures are only 156 (39\%). This study was approved in accordance with the ethical standards of our 


\section{Journal of Orthopedics \& Bone Disorders}

hospital committee on human experimentation, and the informed consent of all patients was obtained. Statistic analysts using MS Excel carried out statistical analysis.

\section{Discussion}

According to $\mathrm{AO}$ foundation, fractures of the calcaneum are common and they are approximately $60 \%$ of tarsal injuries. But in our study it is rear fracture only 39\% [5]. In Brazil the ratio between male and female is 5.5:1 and in Scotland male to female ratio $2.4: 1$ but in our study is $4: 1$. In Rio de Janeiro is uncommon as in Slovakia [6,7]. In Scotland 15 patients less than 19 years old affected yearly, but in Kosice 3.4 patients under 20 years old yearly had calcaneal fracture [7].

\section{Conclusion}

From these results we find out that calcaneal fracture is rare, affecting men 4 times more than women due to the nature of work (four out of every five people). Calcaneal fracture is common cause of disability. The results of this study are expected to contribute to providing an information base that helps planning and decision making by the people in charge in developing appropriate strategies to deal with safety at work site. Other studies are recommended for prevention and treatment.

\section{Acknowledgment}

We thank all the staff of our trauma clinic for their kind support and intensive work.

\section{Conflict of Interest Statement}

The authors declared that the research was conducted in the absence of any commercial or financial relationship that could be construed as a potential conflict of interest.

\section{References}

1. Haapasalo $H$, Laine $H J$, Mäenpää $H$, Wretenberg $P$, Kannus P, et al. (2017) Epidemiology of calcaneal fractures in Finland. Foot Ankle Surg 23(4): 321-324.

2. Greenspan A (2014) Orthopedic Imaging: A Practical Approach. Lippincott Williams and Wilkins, pp: 1192.

3. Miller M, Thompson S (2015) Millers Review of Orthopaedics. $7^{\text {th }}$ (Edn.), Elsevier, pp: 904.

4. Solomon L, Warwick D, Nayagam S (2014) Apley and Solomon's Concise System of Orthopaedics and Trauma. 4th (Edn.), CRC Press, pp: 504.

5. Buckley R, Moran C, Apivatthakakul T (2017) AO Principles of Fracture Management. AO Foundation, $3^{\text {rd }}$ (Edn.), Clavadelerstrasse 8, 7270 Davos Platz, Switzerland, pp: 999.

6. Leite C, Macedo R, Saito G, Marcos Sakaki H, Kojima K, et al. (2018) Epidemiological study on calcaneus fractures in a tertiary hospital. Revista Brasileira de Ortopedia 53(4): 472-476.

7. MJ Mitchell M, McKinley J, Robinson C (2009) The epidemiology of calcaneal fractures. The Foot 19(4): 197-200. 